\title{
Urinary calculi as consequence of renal infection and relationship between their incidence and different dietary factors
}

\author{
Georgeta Sofia Pintilie (Popescu) $)^{1,2}$, Ioana Varga ${ }^{3}$, Iulian Ionescu ${ }^{4}$ and Anisoara Preda ${ }^{5}$ \\ ${ }^{1}$ Polytechnic University Faculty of Industrial Chemistry and Environment Chemistry - Timisoara, Romania, ${ }^{2}$ University of \\ Agricultural Science and Veterinary Medicine Timişoara, Faculty of Food Products Technology, Department of Chemistry, \\ 119 Calea Aradului, 300 645, Timisoara, Romania, ${ }^{3}$ 'Transilvania' University Faculty of Medicine, Brasov, Neurology and \\ Psychiatry Hospital - Brasov, 7-9 Prundului Street, Brasov, ${ }^{4}$ The West Medical Centre - 1 Calea Fagarasului, Brasov and \\ ${ }^{5}$ National R\&D Institute for Cryogenics and Isotopic Technologies - ICIT Rm-Vâlcea, 240050 Valcea, Romania
}

Urinary tract calculi are a universal source of renal pathology. Humans and animals both suffer from the urinary stone problem. Ammonium magnesium phosphate hexahydrate, also known as struvite, a mineral, is important due to its occurrence as crystallites in urine and as a type of kidney stone ${ }^{(1,2)}$. Frequent urinary tract infections result in the formation of the struvite calculi known as triple phosphate stone, infection stone or urase stone.

The calcium and magnesium concentrations were determined by atomic absorption spectroscopy. The nature of calculi is investigated with FTIR spectroscopy and X-ray diffraction methods. The study also involved people who currently use water from the well (natural water), especially from rural areas, in regions with mineral water springs, not only people who consumed tap water. The intake of magnesium and calcium from well or tap water and used in cooking is 10-21\% of the total dietary intake for Romanian population. In this study, the relationship between the incidence of struvite stones, water cations composition and the geological features on the basis of our study of urolithiasis performed in different county areas in Romania was examined. Seven hundred and nine samples (calculi) were collected in a period of 3 years (2000-2003) from 26\% of urological departments in Romania. From that, 79 samples are magnesium ammonium phosphate (MAP) calculi. The 60 localities, towns and villages, with well and/or tap water are classified into six groups according to magnesium-calcium ratio of their tap or well water. In accordance with the geological survey map of Romania, our localities are from five categories of geological features (sedimentary rock, granite, basalt, limestone and metamorphic rock). There was a significant positive correlation between the percentages of infection stones and the magnesium-calcium ratio of dietary water in each locality (Table 1).

Table 1. Relationship between incidence and infection stones, magnesium-calcium ratio of intake water and geological features

\begin{tabular}{|c|c|c|c|c|c|}
\hline \multirow{3}{*}{$\begin{array}{l}\mathrm{Mg}: \mathrm{Ca} \text { ratio } \\
\text { in water }\end{array}$} & \multicolumn{5}{|c|}{ Percentage of infection stone (of the mean of all sample) } \\
\hline & $\leq 5 \%$ & $5-7 \%$ & $7-9 \%$ & $9-13 \%$ & $\geq 13 \%$ \\
\hline & \multicolumn{5}{|c|}{ Number of sample (number and type of geological features) } \\
\hline $0.9-1.5$ & & $1(\mathrm{~S})$ & 2(B) & & $3(2 S), 5(4 B)$ \\
\hline $0.5-0.9$ & & & $1(\mathrm{~S}), 2(\mathrm{~B})$, & $2(\mathrm{~S}), 1(\mathrm{~B}), 1(\mathrm{M})$ & $6(4 S), 2(2 B)$ \\
\hline $0.3-0.5$ & & & $2(2 \mathrm{G})$ & $1(\mathrm{~S}), 2(\mathrm{~B}), 2(2 \mathrm{G})$ & $3(2 \mathrm{~S}), 2(\mathrm{~B})$ \\
\hline $0.1-0.3$ & $1(\mathrm{~L})$ & $2(\mathrm{G})$ & $1(\mathrm{~S})$ & $2(\mathrm{~S}), 1(\mathrm{~B}), 1(\mathrm{G})$ & $1(\mathrm{~S}), 2(\mathrm{~B}), 1(\mathrm{G}), 1(\mathrm{M})$ \\
\hline $0.07-0.1$ & $1(\mathrm{G}), 1(\mathrm{~L})$ & $1(\mathrm{G})$ & $4(2 \mathrm{G}), 2(2 \mathrm{~L})$ & $5(4 \mathrm{G})$ & $1(\mathrm{G})$ \\
\hline$<0.07$ & $2(\mathrm{G}), 2(\mathrm{M})$ & & $3(2 \mathrm{G}), 2(2 \mathrm{M})$ & $2(2 \mathrm{G}), 1(\mathrm{M}), 1(\mathrm{~L})$ & \\
\hline
\end{tabular}

$\mathrm{S}$, sedimentary rock areas; $\mathrm{B}$, basalt region; $\mathrm{M}$, metamorphic rock areas; $\mathrm{G}$, granite areas; L, limestone areas.

In our previously study ${ }^{(2-4)}$, we showed that magnesium from intake of water can be considered to prevent the formation of calciumcontaining urinary calculi (such as calcium oxalate monohydrate and dihydrate, calcium phosphate, brushite, etc.), because magnesium have an inhibitory effect on the formation of calcium calculi. From our previous ${ }^{(2-4)}$ and present studies, we show that a high magnesiumcalcium ratio affect the formation of magnesium-containing stones such as magnesium ammonium phosphate (struvite). Therefore, we examined the relationship between the incidence of struvite stones and dietary water mineral content. The magnesium-calcium ratio of consumed water was found to correlate positively with the incidence of struvite stones. The tap water magnesium-calcium ratio was high in regions of basalt and sedimentary rock and was low in granite and limestone areas. The incidence of struvite stones in the regions of basalt and sedimentary rock was higher than that in the granite and limestone areas. Thus, this study suggested that the incidence of struvite stones is related to the magnesium-calcium ratio of intake water and to the regional geology.

We acknowledge Professor Dr Petru Dragan from the University of Medicine Timisoara - Clinical Urology Department, for help in performing these studies.

1. Deng F \& Ouyang J-M (2006) Mater Sci Eng C 26, 688.

2. Popescu GS, Garban G, Garban Z et al. (2005) In Proceedings of the 5th International Symposium: 'Trace Elements in Human: New Perspectives', S Ermidou-Pollet \& S Pollet (editors) pp. 263-271 (Athens).

3. Popepscu GS, Ionescu I \& Pop AM (2003) In Proceedings of the 4th International Symposium: 'Trace Elements in Human: New Perspectives', S Ermidou-Pollet \& S Pollet (editors) pp. 471-477 (Athens).

4. Popescu S, Garban G, Grecu R et al. (2006) In Proceeding 'Macro and Trace Elements', 23. Workshop, September 2006 (M Anke M et al. editors), Friedrich-Schiller-University Jena, Verlang Harald Schubert, pp. 271-278 (Liepzig). 